\title{
News Releases and Public Service Announcements ${ }^{1}$
}

\author{
Ricky Telg ${ }^{2}$
}

This publication about news releases and public service announcements is the third of a four-part series on media relations. This series also covers media relations strategies, working with the news media, and media interview skills.

\section{Introduction}

You may be called upon to write a news release-also called a press release-or public service announcements (PSAs) about your organization's activities, interesting news, or important events. This publication provides tips about how to write news releases and PSAs.

\section{News Releases}

A news release provides reporters with the basics they need to develop a news story and is sent to news media to announce something that has news value.

Your news release needs to be local and newsworthy. It should be brief-no more than two double-spaced pages in length. Most importantly, your news release must be well written. It is a good idea to send the release to the person who likely would cover the event; do not just send it to "The Editor." Most news media outlets list reporters, their phone numbers, and e-mail addresses on their websites.

\section{Writing News Releases}

A news release is written in just the same way that reporters write news stories. Following are some elements of newswriting style to keep in mind:
- Inverted pyramid structure: Include the most important information first, followed in descending order by less-important information.

- 5 Ws and $H$ : The most important of these questions should be answered in the lead: Who? What? When? Where? Why? How? Others should be answered later in the story.

- Lead: This is the first sentence and is used to grab the reader's attention.

- Short paragraphs: Paragraphs usually run one to two sentences in length. Rarely do you see paragraphs of more than three sentences in a news story.

- Quotations: Quotations are the exact words of someone talking. Quotations can bring life to your story.

- Associated Press style: News releases must follow AP style.

- Proofreading: News releases should be as free of grammar, punctuation, and spelling errors as possible. Proofread news releases several times.

The lead, or first sentence, provides the most important information. The second paragraph should provide any information that immediately helps the reader. For example, for a news release about an upcoming event, the second paragraph may provide the location and exact time of the event, along with information about registration

1. This document is WC113, one of a series of the Department of Agricultural Education and Communication, Florida Cooperative Extension Service, Institute of Food and Agricultural Sciences, University of Florida. Original publication date August 2011. Visit the EDIS website at http://edis.ifas.ufl.edu.

2. Ricky Telg, professor, Department of Agricultural Education and Communication, Florida Cooperative Extension Service, Institute of Food and Agricultural Sciences, University of Florida 
fees. This part of the news release often explains the "how" question.

Follow the "how" with information that provides context. This may be the "why" of the story. For example, why is it important for people to attend your event? The last part of the story provides useful detail and history. Many times this is a brief paragraph at the end of the story that explains a little bit about the event. For news releases that feature an organization, the last paragraph usually contains information about the organization, such as the number of members and how the organization supports the community.

In addition to imitating newswriting style, news releases should be structured as follows:

- Spacing and length: News releases should be doublespaced, no more than two pages in length, and should never be handwritten.

- Identification: The name, phone number, and e-mail address of the news release writer should be provided, as well as the names, phone numbers, and e-mail addresses of those who were interviewed.

- Release date: The release date is at the top of the news release and indicates when it should be run and when it should not be considered. If a news release can be run or aired as soon as a reporter receives it, the phrase "For Immediate Release" is written. If the release has an ending date, then the release date should include something like this: "Run Until Dec. 4."

News releases about events can either be preevent or postevent stories. A preevent news release is sent to news media before an event happens in order to generate coverage of the event in newspapers and on television and radio broadcasts. A postevent news release is provided to news media after an event happens. These are used frequently at county fairs to summarize the fair competition winners.

\section{Public Service Announcements}

A public service announcement (PSA) is a free advertisement that the news media distribute to highlight information about nonprofit organizations' programs, activities, or events. The message in the PSA should be clear. Include the date and time of the event and any information that the audience may need, such as a web address or telephone number to learn more.
Keep in mind that you do not have control over when or if PSAs run. On television, PSAs may run late at night or in the early morning when few paid advertisements run. However, any free airtime is better than nothing. Radio stations can be better about airing PSAs because they do not take much time to produce. Radio announcers also may read the information on-air.

\section{Writing PSAs}

Radio and television announcers may help you write the PSA. If you have "live" copy for announcers to read on-air, make sure it is complete. It should have the phone number and e-mail address of someone in your organization to contact. Try to make the PSA as brief and as easily readable as possible. A 15-second radio PSA, for example, is only about 38 words, and a 30 -second radio PSA is approximately 75 words, so your message needs to be to the point. Write the PSA in a conversational style with sentences of 12 to 15 words each. Do not use jargon.

For PSAs printed in newspapers and magazines, design the PSA so that people's eyes are drawn to it. This usually means making the visual design appealing with an eyecatching headline, graphic, or photograph.

\section{Additional Information}

Diggs-Brown, B., \& Glou, J. (2004). The PR style guide: Formats for public relations practice. Belmont, CA: Wadsworth.

Marsh, C., Guth, D. W., \& Short, B. P. (2005). Strategic writing: Multimedia writing for public relations, advertising, sales and marketing, and business communication. Boston, MA: Pearson Education.

Telg, R. (2000). Getting out the news. Retrieved October 23, 2010, from http://mediarelations.ifas.ufl. edu/2effectivemediarelations.htm 